\title{
Decreased Skeletal Muscle Mass After Neoadjuvant Therapy Correlates with Poor Prognosis in Patients with Esophageal Cancer
}

\author{
JIAJIA LIU ${ }^{1}$, SATORU MOTOYAMA ${ }^{1,2}$, YUSUKE SATO ${ }^{1}$, AKIYUKI WAKITA ${ }^{1}$, \\ YUTA KAWAKITA $^{1}$, HAJIME SAITO ${ }^{1}$ and YOSHIHIRO MINAMIYA ${ }^{1}$ \\ Departments of ${ }^{1}$ General Thoracic Surgery, and ${ }^{2}$ Comprehensive Cancer Control, \\ Akita University Graduate School of Medicine, Akita, Japan
}

\begin{abstract}
Background: Loss of skeletal muscle is predictive of a poor prognosis in patients with various malignant lesions. Our aim was to determine whether changes in skeletal muscle after neo-adjuvant therapy (NAT) predict prognosis in patients with esophageal squamous cell carcinoma (ESCC) undergoing esophagectomy. Patients and Methods: The cross-sectional areas of the psoas muscles were measured on computed tomographic images collected at the initial visit, preoperatively and postoperatively in 84 patients. The psoas muscle index (PMI) was calculated by normalizing the cross-sectional areas to the patients' heights. Results: Low PMI at the initial visit was not associated with a poor prognosis. The majority of patients showed decreased PMI after NAT and surgery. The group in which the postNAT PMI decreased had poorer overall survival than group without PMI decrease ( $p=0.025)$. Conclusion: Decreased $P M I$ correlates well with a poor prognosis in patients with ESCC. Changes in PMI over a period of time may have greater sensitivity when evaluating prognosis than the PMI at any single time point.
\end{abstract}

Esophageal squamous cell carcinoma (ESCC) is a highly aggressive malignant tumor with a poor prognosis (1). The operation for ESCC is one of the most challenging of digestive surgeries; it is highly invasive and requires a high degree of technical expertise. In addition, the operative and recovery times are both long, and the surgery is accompanied by frequent postoperative complications $(2,3)$. Although

Correspondence to: Jiajia Liu, Department of General Thoracic Surgery, Akita University Graduate School of Medicine, 1-1-1 Hondo, Akita 010-8543, Japan. Tel: +81 188846132, Fax: +81 188362615, e-mail: liujiajia517@yahoo.co.jp

Key Words: Skeletal muscle, esophageal cancer, neo-adjuvant therapy, prognosis. introduction of minimally-invasive esophagectomy has reduced surgical stress somewhat, preoperative chemotherapy or chemoradiotherapy is now standard treatment, which introduces a different kind of surgical stress into today's therapy for esophageal cancer. However, there have been few studies on the impact of preoperative conditions on the outcomes of patients with ESCC (4).

Sarcopenia is characterized by degenerative loss of skeletal muscle mass and strength. Loss of skeletal muscle has been identified as predictive of a poor prognosis in patients with many benign and malignant lesions, including liver cirrhosis (5), chronic obstructive pulmonary disease (6), lung cancer (7), cholangiocarcinoma (8), hepatocellular carcinoma (9), metastatic renal cell carcinoma (10), pancreatic cancer (11), colorectal cancer (12), melanoma (13), breast cancer (14), and diffuse large B-cell lymphoma (15), among others. In patients with ESCC without lymphnode involvement, skeletal muscle loss is associated with reduced overall survival (16), as well as postoperative respiratory complications, anastomotic insufficiency and toxicity during neoadjuvant chemotherapy (NAC) (16-18).

However, nearly all studies on sarcopenia to date have focused on the absolute amount of skeletal muscle mass at only a single time point (initial visit or preoperative condition), not the change of skeletal muscle mass over time. In this retrospective study, we examined the change in the psoas muscle index (PMI) during the period extending from the initial visit until after preoperative neoadjuvant therapy and then after surgery, and clarified the relationship between changes in PMI and clinical outcomes in patients with ESCC undergoing esophagectomy.

\section{Patients and Methods}

Patients. This study was approved by the Ethics Committee of Akita University (Approval number: 547) and was conducted in accordance with the Declaration of Helsinki of 1996. There were 84 
adult patients with cStage IB, II or III ESCC who underwent NAT [19 NAC and 65 NAC with radiotherapy (NACRT)] following esophagectomy at Akita University Hospital from Sep. 2008 to Jan. 2015. The 72 males and 12 females had a median age of 63 years (range $=40-74$ years). For all patients, tumor staging was based on the International Union against Cancer tumor-node-metastasis (TNM) Classification of Malignant Tumors (seventh edition) (19). Pretreatment diagnostic evaluation included esophagography, endoscopy, computed tomography (CT), and ${ }^{18} \mathrm{~F}$-fluorodeoxyglucose positron-emission tomography $\mathrm{CT}$.

PMI measurement. The cross-sectional areas of the right and left psoas muscles were measured by manually tracing them on CT images at the level of the middle of third lumbar vertebra (L3). Measurements were made using images taken on the initial visit, post-NAT and 3 months postoperatively. PMI was calculated by normalizing the cross-sectional areas to the patients' heights $\left(\mathrm{cm}^{2} / \mathrm{m}^{2}\right)(20)$ (Figure 1A).

Treatment strategy. For all patients, treatment strategies were defined at a conference attended by radiologists, physicians, and surgeons. In general, patients with locally advanced tumors or nodepositive tumors underwent NACRT. Briefly, the radiotherapy consisted of $40 \mathrm{~Gy}$ in 20 fractions. The chemotherapy consisted of protracted infusion of 5 -fluorouracil $\left(800 \mathrm{mg} / \mathrm{m}^{2} /\right.$ day $)$ on days $1-5$, combined with cisplatin or nedaplatin $\left(80 \mathrm{mg} / \mathrm{m}^{2} /\right.$ day $)$ on day 1 . This chemotherapy protocol was repeated twice with 3-4 week intervals in between. Our standard operative procedure was transthoracic or thoracoscopic esophagectomy with three-field lymphadenectomy of the mediastinal (involving the periesophageal region and areas around the trachea and bilateral main bronchus), abdominal (involving the perigastric region and areas around the celiac axis) and cervical (involving the bilateral periesophageal region and supraclavicular region) lymph nodes (21). Reconstruction commonly involved inserting a gastric tube or pedicled colon (22). A jejunostomy feeding tube was used for patients who needed reconstruction with a pedicled colon graft, or were in poor general condition.

Statistical analysis. Continuous variables are presented as medians (minimum-maximum) and differences between two groups were analyzed using the Mann-Whitney $U$-test. Categorized data were analyzed using the Pearson chi square test or Fisher exact probability test. The survival time distribution was determined using the Kaplan-Meier method with the log-rank test. The hazard ratios of PMI change for mortality were assessed using Cox's proportional hazards regression models. All statistical analyses were performed using the JMP10.0 (SAS Institute, Cary, NC, USA) and yielded two-sided $p$-values. Values of $p<0.05$ were considered statistically significant.

\section{Results}

PMI in patients with ESCC. Each patient's percentage PMI at the three time points (initial visit, post-NAT, and postoperation) is shown in Figure 1B. The median PMIs at the initial visit, post-NAT and post-operation were 4.63 $($ range $=1.77-6.89), 4.54 \quad($ ange=1.59-6.89 $)$ and 3.99 (ange $=1.53-7.17$ ), respectively. Compared to PMI at the

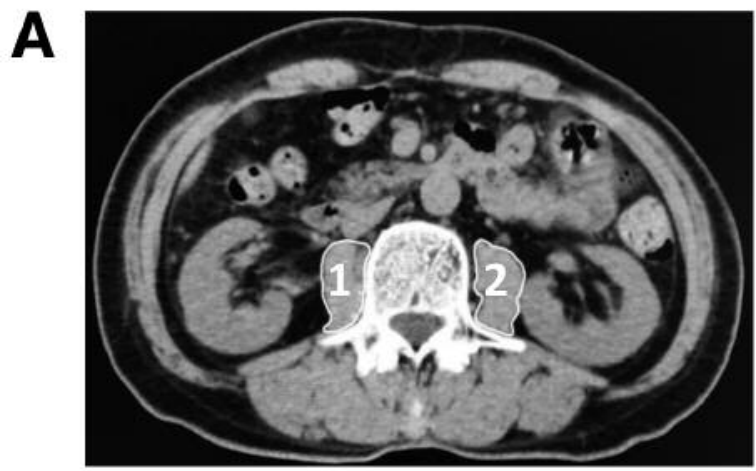

$\operatorname{PMI}\left(\mathrm{cm}^{2} / \mathrm{m}^{2}\right)=($ area $1+$ area2$) /$ body height ${ }^{2}$

B

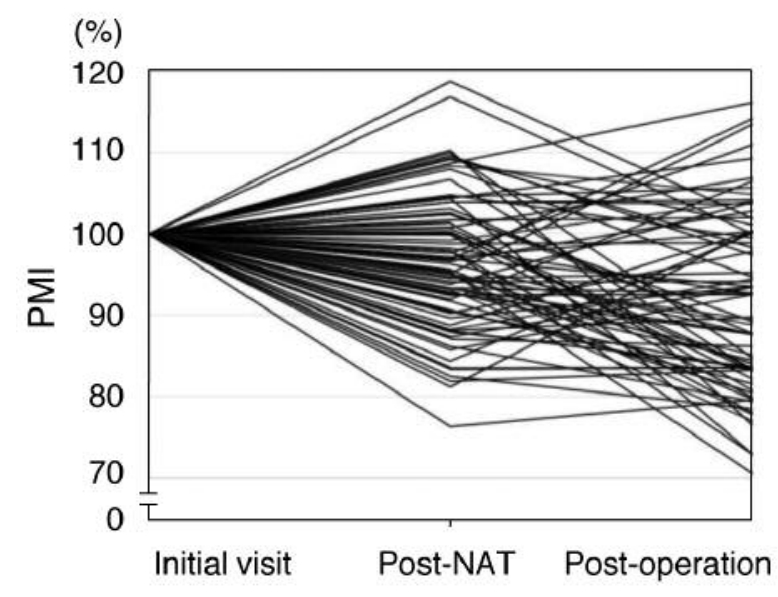

C

(\%)

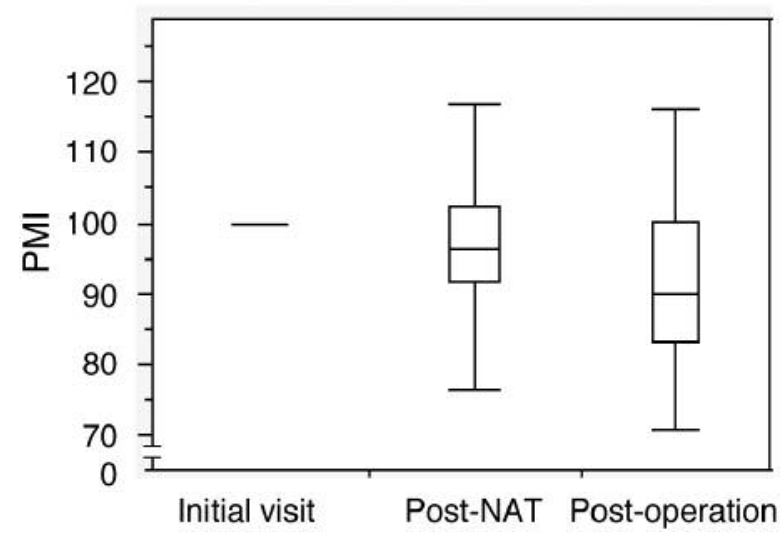

Figure 1. A: Manual tracing of the areas of the bilateral psoas muscle. B: Psoas muscle index (PMI) in 84 patients at different time points. $C$ : Box and whisker plot of PMI at different time points. The post-neoadjuvant therapy (NAT) PMI significantly decreased $(p=0.0213)$ compared to that at the initial visit and the postoperative PMI decreased even further ( $p=0.0001)$. 
Table I. Psoas muscle index (PMI) in patients with esophageal squamous cell carcinoma.

\begin{tabular}{|c|c|c|c|c|c|c|c|}
\hline Clinical feature & No. & $\begin{array}{c}\text { Initial visit } \\
\text { PMI }\left(\mathrm{cm}^{2} / \mathrm{m}^{2}\right)\end{array}$ & $p$-Value & $\begin{array}{c}\text { Post-NAT } \\
\text { PMI }\left(\mathrm{cm}^{2} / \mathrm{m}^{2}\right)\end{array}$ & $p$-Value & $\begin{array}{l}\text { Postoperative } \\
\text { PMI }\left(\mathrm{cm}^{2} / \mathrm{m}^{2}\right)\end{array}$ & $p$-Value \\
\hline ALL cases & 84 & $4.63(1.77-6.89)$ & & $4.54(1.59-6.89)$ & & $3.99(1.53-7.17)$ & \\
\hline Age (years) & & & 0.247 & & 0.137 & & 0.602 \\
\hline$<65$ & 51 & $4.70(1.77-6.89)$ & & $4.62(1.59-6.71)$ & & $4.17(1.65-7.17)$ & \\
\hline$\geq 65$ & 33 & $4.53(2.06-6.40)$ & & $4.21(1.95-5.96)$ & & $3.95(1.71-6.60)$ & \\
\hline Gender & & & $<0.0001 *$ & & $0.0001^{*}$ & & $0.0016^{*}$ \\
\hline Male & 72 & $4.77(2.20-6.89)$ & & $4.63(1.95-6.71)$ & & $4.19(1.38-7.17)$ & \\
\hline Female & 12 & $3.55(1.77-4.65)$ & & $3.23(1.59-4.44)$ & & $3.34(1.65-3.99)$ & \\
\hline Clinical tumor depth & & & 0.407 & & 0.435 & & 0.579 \\
\hline cT1-2 & 15 & $4.36(2.69-6.18)$ & & $4.38(2.80-6.71)$ & & $3.87(2.39-7.17)$ & \\
\hline cT3-4a & 69 & $4.70(1.77-6.89)$ & & $4.61(1.59-6.58)$ & & $4.04(1.65-6.60)$ & \\
\hline Clinical LN involvement & & & 0.706 & & 0.562 & & 0.796 \\
\hline $\mathrm{cN} 0-1$ & 58 & $4.57(2.06-6.40)$ & & $4.49(1.95-6.71)$ & & $3.99(1.71-7.17)$ & \\
\hline $\mathrm{cN} 2-3$ & 26 & $4.71(1.77-6.89)$ & & $4.57(1.59-6.58)$ & & $3.85(1.65-6.57)$ & \\
\hline NAT method & & & 0.401 & & 0.368 & & 0.571 \\
\hline NAC & 19 & $4.77(2.78-6.40)$ & & $4.54(2.65-6.49)$ & & $3.99(2.93-6.60)$ & \\
\hline NACRT & 65 & $4.53(1.77-6.89)$ & & $4.49(1.59-6.71)$ & & $3.97(1.65-7.17)$ & \\
\hline Pathological tumor depth & & & 0.491 & & 0.369 & & 0.179 \\
\hline pT0-2 & 47 & $4.53(2.06-6.40)$ & & $4.45(2.19-6.71)$ & & $3.82(1.71-7.17)$ & \\
\hline pT3-4a & 37 & $4.83(1.77-6.89)$ & & $4.83(1.59-6.58)$ & & $4.56(1.65-6.57)$ & \\
\hline Pathological LN involvement & & & 0.956 & & 0.612 & & 0.806 \\
\hline pN0-1 & 67 & $4.65(2.06-6.89)$ & & $4.53(1.95-6.71)$ & & $3.99(1.71-7.17)$ & \\
\hline $\mathrm{pN} 2-3$ & 17 & $4.61(1.77-6.59)$ & & $4.49(1.59-6.49)$ & & $4.22(1.65-6.60)$ & \\
\hline Histological response to NAT & & & 0.160 & & 0.180 & & 0.155 \\
\hline Grade $0-1$ & 33 & $4.77(2.20-6.89)$ & & $4.66(1.95-6.49)$ & & $4.41(2.20-6.60)$ & \\
\hline Grade $2-3$ & 51 & $4.53(1.77-6.40)$ & & $4.40(1.59-6.71)$ & & $3.80(1.65-7.17)$ & \\
\hline
\end{tabular}

Values are median (minimum-maximum). NAT: Neoadjuvant therapy; NAC: neoadjuvant chemotherapy; NACRT: neoadjuvant chemoradiotherapy; LN: lymph node. *Considered significant.

initial visit, the post-NAT PMI was significantly lower $(p=0.0213)$, and the postoperative PMI was lower still $(p=0.0001)$ (Figure 1C).

The PMIs at the three time points according to age, gender, clinical tumor depth, clinical LNs involvement, NAT method, pathological tumor depth, pathological lymph node involvement and histological response to NAT are summarized in Table I. The PMI recorded in female patients was significantly lower than in male patients at the initial visit $(p<0.0001)$, post-NAT $(p=0.0003)$ and post-operation $(i=0.0016)$. Older patients tended to have lower PMIs than younger patients. The percentage PMI at the three time points according to these factors are shown in Figure 2. Patients with male gender, clinical or pathological tumor progression, NACRT, and lower histological response to NAT tended to have a greater post-NAT PMI decrease, although the effect was not significant.

Initial visit PMI and overall survival. Because female patients had obviously lower PMIs at their initial visits than male patients (median: $4.77 v s .3 .55, p<0.0001$ ), we divided the male and female patients into high- and low-PMI groups using their respective medians as cutoff values. Each group consisted of 42 patients. The two groups had similar overall survival rates $(p=0.814)$, and the group with low PMI did not have a significantly poorer prognosis (Figure $3 \mathrm{~A}$ ).

Post-NAT PMI change and overall survival. In 54 patients (64\%), the post-NAT PMI was lower than that at the initial visit, whereas PMI was increased or unchanged in the remaining 30 patients (36\%). Based on this result, we divided the patients into groups with and without PMI decrease. The backgrounds of the patients in the two groups are summarized in Table II. Age, gender, laboratory data (albumin, hemoglobin and C-reactive protein, tumor features (clinical or pathological tumor depth, lymph node involvement), NAT method and histological response to NAT were comparable between the two groups. However, the group with PMI decrease had a clearly poorer overall survival rate than the group without ( $p=0.025$ ) (Figure 3C), and cancer was the main cause of death in group with PMI decrease $(p=0.005)$ (Table II).

To further analyze the correlation between decreased PMI and overall survival, we divided the group with PMI 

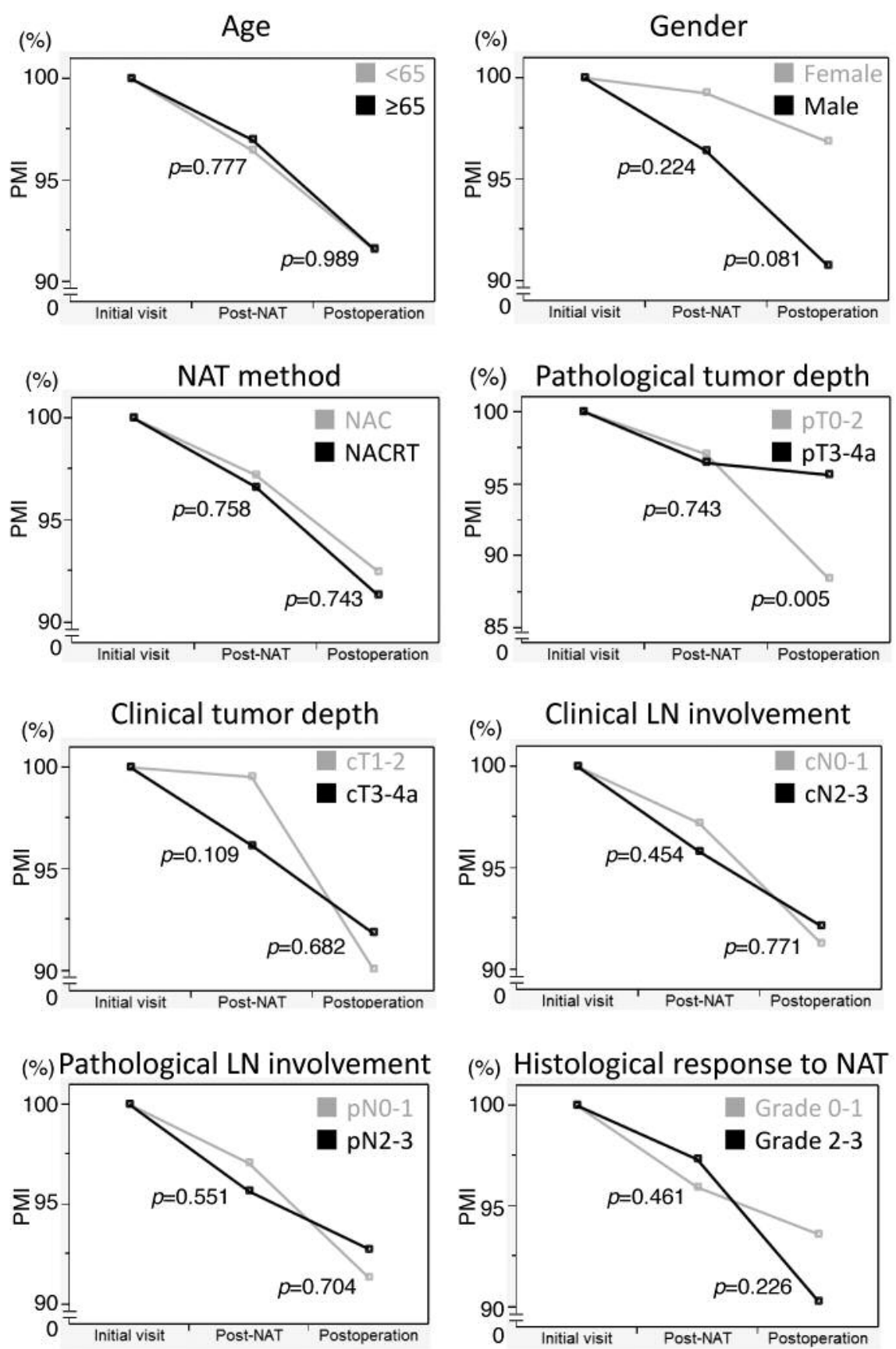

Figure 2. Psoas muscle index (PMI) at initial visit, post-neo-adjuvant therapy (NAT) and postoperatively according to clinicopathological parameters. PMI is given as a percentage of the initial PMI. LN: Lymph node; NAC: neoadjuvant chemotherapy; NACRT: neoadjuvant chemoradiotherapy.

decrease into mildly and severely decreased groups using the median decrease in PMI $(\Delta=0.283)$ as the cut-off value. Both groups contained 27 patients $(50 \%)$. Interestingly, the severely-decreased group had significantly poorer overall survival than the mildlydecreased group $(p=0.003)$ (Figure 3D).
Post-NAT PMI changes and short-term surgical outcome. As shown in Table III, patients in the groups with and without PMI decrease had similar operative times (553 (383-776) vs. 515 (417-804) $\mathrm{min} ; p=0.365)$ and blood loss (635 (1433217) vs. $553(115-2,099) \mathrm{ml} ; p=0.254)$. The overall incidence of complications was $41.7 \%$, and there was no 
A

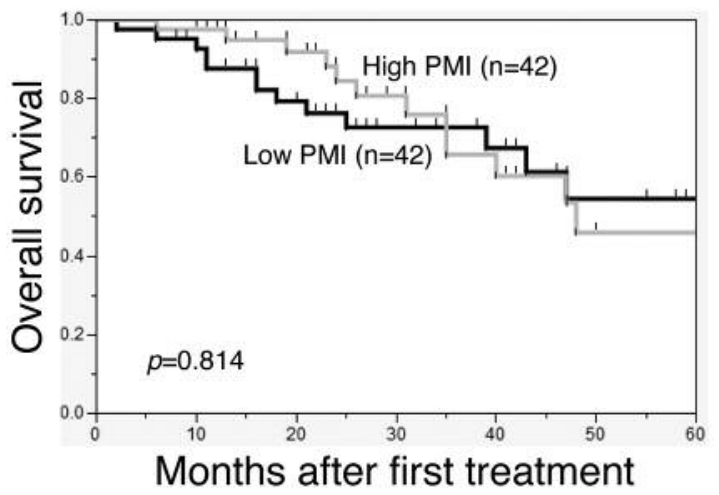

C

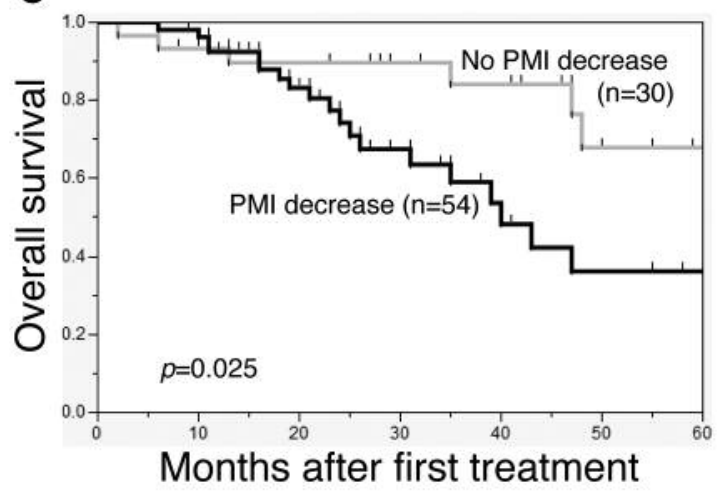

B

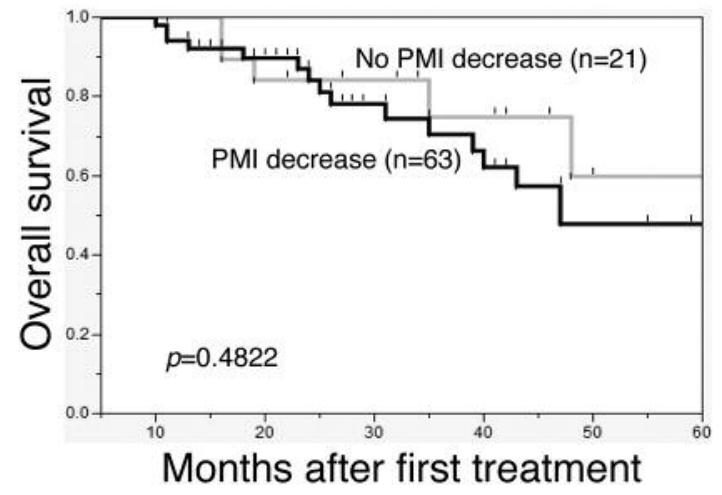

D

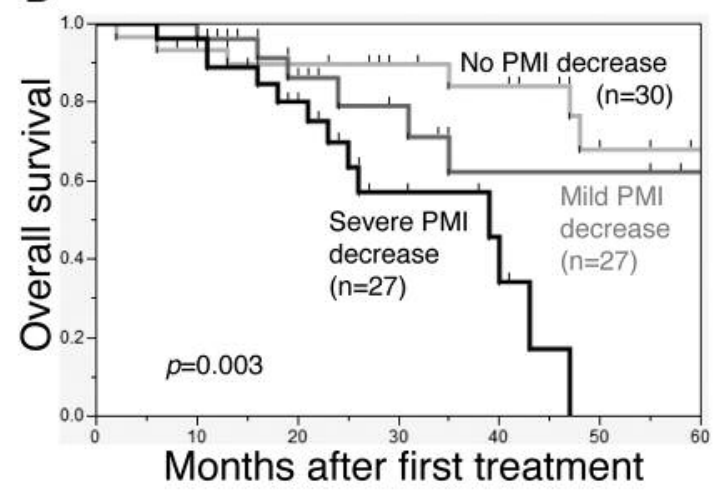

Figure 3. Overall survival stratified according to psoas muscle index (PMI) at initial visit (A), whether or not PMI decreased between the initial visit and postoperatively $(B)$, whether or not PMI decreased between the initial visit and post-neoadjuvant therapy $(N A T)(C)$, and according to severity of PMI decrease (D).

difference in the incidence of any complication (anastomosis leakage, pneumonia, recurrent nerve paralysis, chylothorax) between the two groups. Postoperative mortality and hospital stay duration were also comparable. These results suggest the post-NAT change in PMI is not related to the short-term surgical outcomes.

Cox's proportional hazards regression models. We used Cox's proportional hazards regression models to further investigate which factors independently contribute to overall survival in these patients with ESCC. In the univariate analysis, male gender $(p=0.002)$, decrease in PMI $(p=0.021)$, pathological lymph node involvement $(p=0.030)$, and histological response to NAT $(p=0.026)$ were significant factors. Multivariate analysis showed that male gender $(p=0.005)$ and decreased PMI $(p=0.050)$ were independent risk factors for poorer overall survival. The hazard ratio for decrease in PMI and reduced overall survival was more than 2.4 (Table IV). In the crude, age- and gender-adjusted, and multivariate-adjusted models, the hazard ratios were more than 2.7 for a decrease in PMI (Table V).
Postoperative PMI changes and overall survival. Finally, by comparing the initial visit PMI with the postoperative PMI, the patients were divided into groups with and without postoperative PMI decrease. The group with postoperative PMI decrease included 63 patients $(75 \%)$, while the group without postoperative PMI decrease included 21 patients (25\%). The group with postoperative PMI decrease tended to have poorer overall survival than the group without, although the difference was not significant $(p=0.482)$ (Figure 3B).

\section{Discussion}

The results of this study show that in patients with ESCC, post-NAT PMI decrease is predictive of a poorer prognosis, and the more PMI decreases the worse overall survival appears to be. This observation was confirmed by a Cox's proportional hazards regression analysis in which decreased PMI was an independent risk factor for poorer survival. On the other hand, low PMI at the initial visit or 3 months after esophagectomy was not associated with a poor prognosis. 
Table II. Background of patients with esophageal squamous cell carcinoma in this study.

\begin{tabular}{|c|c|c|c|}
\hline Clinical feature & $\begin{array}{l}\text { No PMI decrease } \\
\qquad(\mathrm{N}=30)\end{array}$ & $\begin{array}{l}\text { PMI decrease } \\
\quad(\mathrm{N}=54)\end{array}$ & $p$-Value \\
\hline Age (years) & $63.5(47-72)$ & $62(40-74)$ & 0.846 \\
\hline \multicolumn{4}{|l|}{ Gender } \\
\hline Female & $5(16.7 \%)$ & $7(13.0 \%)$ & 0.642 \\
\hline Male & $25(83.3 \%)$ & $47(87.0 \%)$ & \\
\hline Clinical tumor depth & & & 0.317 \\
\hline $\mathrm{cT} 1$ & $3(10.0 \%)$ & $2(3.7 \%)$ & \\
\hline cT2 & $5(16.7 \%)$ & $5(9.26 \%)$ & \\
\hline cT3 & $22(73.3 \%)$ & $45(83.33 \%)$ & \\
\hline $\mathrm{c} 4 \mathrm{a}$ & $0(0.0 \%)$ & $2(3.7 \%)$ & \\
\hline \multicolumn{4}{|l|}{ Clinical lymph node } \\
\hline involvement & & & 0.056 \\
\hline $\mathrm{cNO}$ & $1(3.3 \%)$ & $8(14.8 \%)$ & \\
\hline $\mathrm{cN} 1$ & $23(76.7 \%)$ & $26(48.2 \%)$ & \\
\hline $\mathrm{cN} 2$ & $5(16.7 \%)$ & $19(35.2 \%)$ & \\
\hline $\mathrm{cN} 3$ & $1(3.3 \%)$ & $1(1.9 \%)$ & \\
\hline Albumin $(\mathrm{g} / \mathrm{dl})$ & $4.2(3.2-5.1)$ & $4.1(2.9-4.9)$ & 0.154 \\
\hline Hemoglobin (g/dl) & $14.0(10.5-16.0)$ & $13.8(10.1-17.0)$ & 0.929 \\
\hline $\mathrm{CRP}(\mathrm{g} / \mathrm{dl})$ & $0.08(0.01-5.79)$ & $0.13(0.01-5.88)$ & 0.212 \\
\hline \multicolumn{4}{|l|}{ NAT method } \\
\hline NAC & $6(20.0)$ & $13(24.1)$ & 0.669 \\
\hline NACRT & $24(80.0)$ & $41(75.9)$ & \\
\hline Pathological tumor depth & & & 0.710 \\
\hline pT0 & $6(20.0 \%)$ & $15(27.8 \%)$ & \\
\hline pT1 & $7(23.3 \%)$ & $9(16.7 \%)$ & \\
\hline pT2 & $4(13.3 \%)$ & $6(11.1 \%)$ & \\
\hline pT3 & $13(43.3 \%)$ & $22(40.7 \%)$ & \\
\hline pT4a & $0(0.0 \%)$ & $2(3.7 \%)$ & \\
\hline \multicolumn{4}{|l|}{ Pathological LN } \\
\hline involvement & & & 0.389 \\
\hline pNO & $14(46.7 \%)$ & $30(55.6 \%)$ & \\
\hline $\mathrm{pN} 1$ & $11(36.7 \%)$ & $12(22.2 \%)$ & \\
\hline $\mathrm{pN} 2$ & $3(10.0 \%)$ & $10(18.5 \%)$ & \\
\hline $\mathrm{pN} 3$ & $2(6.7 \%)$ & $2(3.7 \%)$ & \\
\hline \multicolumn{4}{|l|}{ Histological } \\
\hline response to NAT & & & 0.194 \\
\hline Grade $0-1$ & $9(30.0 \%)$ & $24(44.4 \%)$ & \\
\hline Grade $2-3$ & $21(70.0 \%)$ & $30(55.6 \%)$ & \\
\hline Prognosis & & & $0.005^{*}$ \\
\hline Cancer death & $3(10.0 \%)$ & $19(35.2 \%)$ & \\
\hline Death from other disease & se $3(10.0 \%)$ & $0(0.0 \%)$ & \\
\hline Alive & $24(80.0 \%)$ & $35(64.8 \%)$ & \\
\hline
\end{tabular}

Values are median (minimum-maximum) or frequency (\%). CRP: C-reactive protein; NAT: neoadjuvant therapy; NAC: neoadjuvant chemotherapy; NACRT: neoadjuvant chemoradiotherapy; LN: lymph node. ${ }^{*}$ Considered significant.

Skeletal muscle loss in patients with cancer may result from fasting, disuse, malnutrition, systemic inflammatory responses or cachexia, a well-known predictor of poor prognosis (23, 24). In patients with ESCC, skeletal muscle loss can also be exacerbated by esophageal obstruction, depending on the stage and location of the tumor. Because ESCC often responds well to chemotherapy and radiotherapy, patients with ESSC often receive more preoperative NAT than other cancer patients. The adverse effects of NAT and the subsequent anatomical changes caused by the surgery can also lead to eating difficulties and severe postoperative malnutrition. In the present study, PMI decreased after NAT in most patients. Interestingly, however, in some patients (35\%) PMI did not decrease, and these patients had a significantly better prognosis. Analysis of the differences between patients who experienced a decrease in PMI and those who did not, revealed that age, gender, laboratory data (albumin, hemoglobin and C-reactive protein), tumor features (clinical or pathological tumor depth, lymph node involvement), NAT method (NAC, NACRT) and histological response to NAT did not account for different responses. Compromised nutritional status may be one explanation for the decrease in PMI, but obviously not the only one, as there was no significant difference in nutritional markers (e.g. albumin and hemoglobin) between the two groups. Genetic factors may also contribute to the different individual responses to NAT (25-27). At present, however, there is no clear explanation and further study will be required to resolve this issue.

One limitation of this study is that we did not collect data on oral ingestion, esophageal obstruction, fasting duration or use of total parenteral nutrition. Moreover, although no differences were found in the tumor features or effect of therapy between patients whose PMI decreased and those whose PMI was unchanged, cancer remained the main reason for death in the group with decreased PMI.

Skeletal muscle loss has been identified as a factor contributing to a poor prognosis in patients with various benign and malignant lesions (28). However, most of those studies focused on the absolute value of the PMI (or other indices) at only a single time point. Likewise, although skeletal muscle loss is associated with a poor prognosis in patients with ESCC (16), few studies have evaluated the change in PMI over time. In fact, because patients with ESCC require multimodal treatment, and there are a variety of factors that may affect nutritional condition during treatment, the nutritional condition of patients with ESCC is in a continuous state of change. Consequently, the changes in PMI during the treatment period likely better reflect the change of state in the patient than the PMI at any one time point. In our patients, all of whom underwent NAT and surgery, an increase or decrease in PMI from the initial visit to post-NAT was a better predictor of prognosis. To the best of our knowledge, this is the first time that change in PMI has been identified as a valuable prognostic factor in ESCC. Given the association between a decrease in PMI and a poor prognosis, preoperative nutritional support may be especially important for patients whose PMI decreased. Through oral nutrient supplementation, and total parenteral nutrition, nutritional management is being improved for patients with ESCC but nutritional intervention remains insufficient. 
Liu et al: Decreased Skeletal Muscle Mass After Neo-adjuvant Therapy for ESCC

Table III. Short-term surgical outcomes of patients with esophageal squamous cell carcinoma in this study.

\begin{tabular}{lccc}
\hline Surgical outcome & No PMI decrease (N=30) & PMI decrease (N=54) & $p$-Value \\
\hline Operation time (min) & $553(383-776)$ & $515(417-804)$ & 0.365 \\
Blood loss (ml) & $635(143-3217)$ & $553(115-2099)$ & 0.254 \\
Complications & & & 0.248 \\
$\quad$ Present & $15(50.0 \%)$ & $20(37.0 \%)$ & $34(63.0 \%)$ \\
$\quad$ Absent & $15(50.0 \%)$ & $6(11.1 \%)$ & 0.506 \\
Anastomotic leakage & $2(6.7 \%)$ & $6(11.1 \%)$ & 0.875 \\
Pneumonia & $3(10.0 \%)$ & $17(31.5 \%)$ & 0.862 \\
Recurrent nerve paralysis & $10(33.3 \%)$ & $2(3.7 \%)$ & 0.243 \\
Chylothorax & $3(10.0 \%)$ & $1(1.9 \%)$ & 0.670 \\
Postoperative mortality & $1(3.3 \%)$ & $25(16-101)$ & 0.444 \\
Hospital stay (days) & $26.5(16-89)$ & \\
\hline
\end{tabular}

Values are median (minimum-maximum) or frequency (\%). PMI: Psoas muscle index. ${ }^{*}$ Considered significant.

Table IV. Univariate and multivariate analyses for 5-year-survival (Cox's proportional hazards regression models)

\begin{tabular}{|c|c|c|c|c|c|c|}
\hline \multirow[b]{2}{*}{ Factor } & \multicolumn{3}{|c|}{ Univariate analysis } & \multicolumn{3}{|c|}{ Multivariate analysis } \\
\hline & Hazard ratio & $95 \% \mathrm{CI}$ & $p$-Value & Hazard ratio & $95 \% \mathrm{CI}$ & $p$-Value \\
\hline Age $(<65 v s . \geq 65$ years $)$ & - & $0.8902-4.6268$ & 0.0901 & & & \\
\hline Gender (female $v s$. male) & $1.8109 \times 10^{9}$ & $2.6405--$ & $0.0020^{*}$ & $1.6198 \times 10^{9}$ & 2.2113-- & $0.0048^{*}$ \\
\hline Initial visit PMI (high vs. low) & - & $0.8041-4.1407$ & 0.1549 & & & \\
\hline $\mathrm{cT}(1-2$ vs. 3-4) & - & $0.6430-13.5551$ & 0.2398 & & & \\
\hline $\mathrm{cN}(0-1$ vs. 2-3) & - & $0.6058-3.0766$ & 0.4217 & & & \\
\hline NAT (NAC vs. NACRT) & - & $0.7812-4.0802$ & 0.1591 & & & \\
\hline PMI change (increase vs. decrease) & 2.7790 & $1.1560-7.7210$ & $0.0214^{*}$ & 2.4353 & $1.0000-6.8347$ & $0.0500^{*}$ \\
\hline урт (0-2 vs. 3-4a) & - & $0.9744-5.1350$ & 0.0580 & & & \\
\hline ypN (0-1 vs. 2-3) & 2.5417 & $1.0986-5.6331$ & $0.0302 *$ & - & $0.9465-5.4561$ & 0.0653 \\
\hline Histological response to NAT (grade 2-3 vs. 0-1) & 2.4757 & $1.1117-5.8693$ & $0.0263^{*}$ & - & $0.7618-4.1438$ & 0.1931 \\
\hline Complication (negative $v s$. positive) & - & $0.7119-3.5398$ & 0.2634 & & & \\
\hline
\end{tabular}

PMI: Psoas muscle index; NAT: neoadjuvant therapy; NAC: neoadjuvant chemotherapy; NACRT: neoadjuvant chemoradiotherapy; ypT: post-therapy pathological tumor depth; ypN: post-therapy pathological lymph node involvement. ${ }^{*}$ Considered significant.

Table V. Hazard ratios per PMI decrease for 5-year-survival (Cox's proportional hazards regression models).

\begin{tabular}{|c|c|c|c|c|}
\hline \multirow[b]{2}{*}{ Crude (PMI decrease only) } & \multirow{2}{*}{$\begin{array}{c}\text { Hazard ratio } \\
2.7790\end{array}$} & \multicolumn{2}{|c|}{$95 \% \mathrm{CI}$} & \multirow{2}{*}{$\frac{p \text {-Value }}{0.0214 *}$} \\
\hline & & 1.1560 & 7.7210 & \\
\hline Adjusted for age, gender & 2.8251 & 1.1677 & 7.8874 & $0.0202 *$ \\
\hline Adjusted for age, gender, ypT, ypN and histological response to NAT & 2.8266 & 1.0204 & 8.9323 & $0.0454^{*}$ \\
\hline Adjusted for age, gender, ypT, ypN, histological response to NAT and complication & 3.1406 & 1.0761 & 10.6169 & $0.0356^{*}$ \\
\hline
\end{tabular}

We found that male patients had significantly higher PMIs than did female patients (Table I), which is consistent with other past findings $(16,17)$. Notably, however, our 12 female patients all survived 5 years. This is significantly better than the male patients, although the males and females had comparable tumor features at their initial visits. Different pathogenic mechanisms in different genders may be responsible for the different prognoses. Discovering the mechanisms by which gender affects prognosis is imperative in future projects. 
Compared to the post-NAT decrease in PMI, the postoperative PMI decrease showed more individual variation. As a result, postoperative PMI changes did not correlate with prognosis. This is consistent with the features of surgery for ESCC (highly invasive, long operation and recovery times, more complications). But if a minimallyinvasive operation can be performed well and totally, individual variation may improve, and postoperative PMI changes may correlate with prognosis.

There have been several reports showing that loss of skeletal muscle mass is associated with an increased risk of anastomotic leak (17), postoperative respiratory complications (16), perioperative infection, longer hospital stays, and prolonged rehabilitation in patients with cancer (29). However, we found no correlation between PMI change and short-term surgical outcomes in the present study. That said, the small number of patients is a limitation of our study, and our findings require confirmation in independent cohort studies in the future.

We found that a decrease of PMI post-NAT is well correlated with a poor prognosis in patients with ESCC. Moreover, the greater the decrease in PMI, the worse overall survival appears to be. In evaluating patients with ESCC, changes in PMI during a particular period may provide greater sensitivity than a single measurement of PMI at one time point.

\section{References}

1 Gertler R, Stein HJ, Langer R, Nettelmann M, Schuster T, Hoefler H, Siewert JR and Feith M: Long-term outcome of 2920 patients with cancers of the esophagus and esophagogastric junction: evaluation of the New Union Internationale Contre le Cancer/American Joint Cancer Committee staging system. Ann Surg 253(4): 689-698, 2011.

2 Allum WH, Stenning SP, Bancewicz J, Clark PI and Langley RE: Long-term results of a randomized trial of surgery with or without preoperative chemotherapy in esophageal cancer. J Clin Oncol 27(30): 5062-5067, 2009.

3 Takeuchi H, Miyata H, Gotoh M, Kitagawa Y, Baba H, Kimura W, Tomita N, Nakagoe T, Shimada M, Sugihara K and Mori M: A risk model for esophagectomy using data of 5354 patients included in a Japanese nationwide web-based database. Ann Surg 260(2): 259-266, 2014.

4 Anandavadivelan P and Lagergren P: Cachexia in patients with oesophageal cancer. Nat Rev Clin Oncol 13(3): 185-198, 2016.

5 Hara N, Iwasa M, Sugimoto R, Mifuji-Moroka R, Yoshikawa K, Terasaka E, Hattori A, Ishidome M, Kobayashi Y, Hasegawa H, Iwata $\mathrm{K}$ and Takei Y: Sarcopenia and sarcopenic obesity are prognostic factors for overall survival in patients with cirrhosis. Intern Med 55(8): 863-870, 2016.

6 Sanders KJ, Kneppers AE, van de Bool C, Langen RC and Schols AM: Cachexia in chronic obstructive pulmonary disease: new insights and therapeutic perspective. J Cachexia Sarcopenia Muscle 7(1): 5-22, 2016.

7 Jafri SH, Previgliano C, Khandelwal K and Shi R: Cachexia index in advanced non-small-cell lung cancer patients. Clin Med Insights Oncol 9: 87-93, 2015.
8 Zhou G, Bao H, Zeng Q, Hu W and Zhang Q: Sarcopenia as a prognostic factor in hepatolithiasis-associated intrahepatic cholangiocarcinoma patients following hepatectomy: a retrospective study. Int J Clin Exp Med 8(10): 18245-18254, 2015.

9 Yabusaki N, Fujii T, Yamada S, Suzuki K, Sugimoto H, Kanda M, Nakayama G, Koike M, Fujiwara M and Kodera Y: Adverse impact of low skeletal muscle index on the prognosis of hepatocellular carcinoma after hepatic resection. Int J Surg 30: 136-142, 2016.

10 Fukushima H, Nakanishi Y, Kataoka M, Tobisu K and Koga F: Prognostic significance of sarcopenia in patients with metastatic renal cell carcinoma. J Urol 195(1): 26-32, 2016.

11 Park I, Choi SJ, Kim YS, Ahn HK, Hong J, Sym SJ, Park J, Cho EK, Lee JH, Shin YJ and Shin DB: Prognostic factors for risk stratification of patients with recurrent or metastatic pancreatic adenocarcinoma who were treated with gemcitabine-based chemotherapy. Cancer Res Treat 48(4): 1264-1273, 2016.

12 Malietzis G, Currie AC, Athanasiou T, Johns N, Anyamene N, Glynne-Jones R, Kennedy RH, Fearon KC and Jenkins JT: Influence of body composition profile on outcomes following colorectal cancer surgery. Br J Surg 103(5): 572-580, 2016.

13 Sabel MS, Lee J, Cai S, Englesbe MJ, Holcombe S and Wang S: Sarcopenia as a prognostic factor among patients with stage III melanoma. Ann Surg Oncol 18(13): 3579-3585, 2011.

14 Villasenor A, Ballard-Barbash R, Baumgartner K, Baumgartner R, Bernstein L, McTiernan A and Neuhouser ML: Prevalence and prognostic effect of sarcopenia in breast cancer survivors: the HEAL Study. J Cancer Surviv 6(4): 398-406, 2012.

15 Lanic H, Kraut-Tauzia J, Modzelewski R, Clatot F, Mareschal S, Picquenot JM, Stamatoullas A, Lepretre S, Tilly H and Jardin F: Sarcopenia is an independent prognostic factor in elderly patients with diffuse large B-cell lymphoma treated with immunochemotherapy. Leuk Lymphoma 55(4): 817-823, 2014.

16 Harada K, Ida S, Baba Y, Ishimoto T, Kosumi K, Tokunaga R, Izumi D, Ohuchi M, Nakamura K, Kiyozumi Y, Imamura Y, Iwatsuki M, Iwagami S, Miyamoto Y, Sakamoto Y, Yoshida N, Watanabe $\mathrm{M}$ and Baba $\mathrm{H}$ : Prognostic and clinical impact of sarcopenia in esophageal squamous cell carcinoma. Dis Esophagus 29(6): 627-633, 2016.

17 Ida S, Watanabe M, Yoshida N, Baba Y, Umezaki N, Harada K, Karashima R, Imamura Y, Iwagami S and Baba H: Sarcopenia is a predictor of postoperative respiratory complications in patients with esophageal cancer. Ann Surg Oncol 22(13): 4432-4437, 2015.

18 Tan BH, Brammer K, Randhawa N, Welch NT, Parsons SL, James EJ and Catton JA: Sarcopenia is associated with toxicity in patients undergoing neo-adjuvant chemotherapy for oesophagogastric cancer. Eur J Surg Oncol 41(3): 333-338, 2015.

19 Sobin L, Gospodarowicz M and Wittekind C: International Union against Cancer. TNM Classification of Malignant Tumors. Seventh Edition. Chichester: Wiley-Blackwell, 2009.

20 Hamaguchi Y, Kaido T, Okumura S, Fujimoto Y, Ogawa K, Mori A, Hammad A, Tamai Y, Inagaki $\mathrm{N}$ and Uemoto S: Impact of quality as well as quantity of skeletal muscle on outcomes after liver transplantation. Liver Transpl 20(11): 1413-1419, 2014.

21 Okuyama M, Motoyama S, Suzuki H, Saito R, Maruyama K and Ogawa J: Hand-sewn cervical anastomosis versus stapled intrathoracic anastomosis after esophagectomy for middle or lower thoracic esophageal cancer: a prospective randomized controlled study. Surg Today 37(11): 947-952, 2007. 
22 Motoyama S, Kitamura M, Saito R, Maruyama K, Sato Y, Hayashi K, Saito H, Minamiya Y and Ogawa J: Surgical outcome of colon interposition by the posterior mediastinal route for thoracic esophageal cancer. Ann Thorac Surg 83(4): 12731278, 2007.

23 Cruz-Jentoft AJ, Baeyens JP, Bauer JM, Boirie Y, Cederholm T, Landi F, Martin FC, Michel JP, Rolland Y, Schneider SM, Topinkova E, Vandewoude M, Zamboni $\mathrm{M}$ and European Working Group on Sarcopenia in Older P: Sarcopenia: European consensus on definition and diagnosis: Report of the European Working Group on Sarcopenia in Older People. Age Ageing 39(4): 412-423, 2010.

24 Evans WJ, Morley JE, Argiles J, Bales C, Baracos V, Guttridge D, Jatoi A, Kalantar-Zadeh K, Lochs H, Mantovani G, Marks D, Mitch WE, Muscaritoli M, Najand A, Ponikowski P, Rossi Fanelli F, Schambelan M, Schols A, Schuster M, Thomas D, Wolfe R and Anker SD: Cachexia: a new definition. Clin Nutr 27(6): 793-799, 2008.

25 Fujita K, Motoyama S, Sato Y, Yoshino K, Sasaki T, Liu J, Niioka T, Anbai A, Minamiya Y and Miura M: IL-6 and MCP-1 genetic polymorphisms are predictive of decreased platelet counts caused by chemoradiotherapy in esophageal cancer. Esophagus 13: 264-269, 2016.
26 Sato Y, Motoyama S, Nanjo H, Ito S, Yoshino K, Sasaki T, Kuribayashi K, Nagaki Y, Imai K, Saito H, Minamiya Y and Ogawa J: REG1A expression status suggests chemosensitivity among advanced thoracic esophageal squamous cell carcinoma patients treated with esophagectomy followed by adjuvant chemotherapy. Ann Surg Oncol 20(9): 3044-3051, 2013.

27 Sato Y, Motoyama S, Nanjo H, Wakita A, Yoshino K, Sasaki T, Nagaki Y, Liu J, Imai K, Saito H and Minamiya Y: CXCL10 Expression status is prognostic in patients with advanced thoracic esophageal squamous cell carcinoma. Ann Surg Oncol 23(3): 936-942, 2016.

28 Shachar SS, Williams GR, Muss HB and Nishijima TF: Prognostic value of sarcopenia in adults with solid tumours: A meta-analysis and systematic review. Eur J Cancer 57: 58-67, 2016.

29 Lieffers JR, Bathe OF, Fassbender K, Winget M and Baracos VE: Sarcopenia is associated with postoperative infection and delayed recovery from colorectal cancer resection surgery. Br J Cancer 107(6): 931-936, 2012.

Received October 1, 2016

Revised October 28, 2016

Accepted October 31, 2016 